\title{
EXPLICACIONES ETIOLÓGICAS DE LA PSICOSIS
}

César Sparrow ${ }^{1}$

\section{RESUMEN}

Aunque todavía se ignora el origen cabal de las psicosis, son expuestos aspectos neurobiológicos fundamentales, reconociéndose la importancia del factor hereditario. A pesar de esto, más de la mitad de la pregunta sobre la etiología de la psicosis queda irresuelta. Las exploraciones del psicoanálisis intentan cubrir este vacío. Se indican las concepciones de sus principales representantes: S. Freud, M. Klein, J. Lacan. Finalmente se puntualizan algunas consideraciones sobre lo somatopsíquico, la idea de salud o normalidad mental, y un alcance de los modernos estudios científicos en consciencia humana y sus relaciones con la física cuántica.

\section{Palabras claves:}

psicosis, etiología, neurobíologia, psicoanálisis, narcisismo, escisión, significante, cuántica.

\begin{abstract}
Although the entire origin of the psychoses is still unknown, are shown fundamental neurobiological aspects, recognizing the factor of heredity. Even though, mostly half the question about the ethiology of psychoses remams unsolued. The explorations of psychoanalysis try to fill this blank. Are remarked the conceptions of their main representative: S. Freud.M. Klein, J. Lacan. Finally, are indicated some considerations about the somatic-psychic, the idea of mental health, sanity or normality, and a reach of modern scientific researchs on human consciousness related to quantum physics.
\end{abstract}

\section{Keywords:}

psychose, ethiology, neurobiology, psychoanalysis, narcsissismus, splitting, significant, quantum.

\footnotetext{
${ }^{1}$ Estudiante de IV año de la Facultad de Psicología de la UNMSM
} 
De aquí en adelante cuando hablemos de «las» psicosis nos estaremos refiriendo en principio a la esquizofrenia, que es un trastorno mental serio caracterizado por pensamientos desordenados, delirios, alucinaciones y muchas veces conductas extrañas; es la enfermedad corresponde a la antigua dementia praecox de Kraepelín que integra además lo que se llamaba paranoia o dementia paranoides (la actual esquizofrenia de tipo paranoide). En cambio, al hablar de «las» psicosis en general, nos estaremos refiriendo además de a la esquizofrenia, a los trastornos afectivos con especificación de psicosis, es decir, las psícosis maníaco depresivas y la depresión psicótica. La psiquiatría moderna define a la psicosis como "una pérdida de las fronteras del ego o un grave deterioro de la evaluación de la realidad», pero hay problemas con esta definición. Primero cabría describir lo que se entiende por «ego», «grave deterioro» o «realidad». 'Tomada demasiado espacio definir el concepto teórico de «ego» desde las diversas escuelas psicológicas, seremos indulgentes con la noción de «grave deterioro» Librándola al sentido común y a la observación fenomenológica, pero apuntaremos dos cosas acerca de la «realidad». Hay un problema al hablar de «realidad», porque no sabemos si nos referimos a la «realidad objetiva» del mundo físico o a una realidad subjetiva determinada por nuestras propias percepciones, pensamientos y sentimientos. Estaríamos hablando así de por lo menos dos tipos de realidad válidas.

Usualmente se entiende que la psicosis implica un desfase del individuo con la realidad, que en este caso seria ¿objetiva o subjetiva? Las corrientes de la clínica que intentaban dar cuenta de la etiología de las psicosis eran sobre lodo de dos órdenes: organicistas y psicogenetistas. En la actualidad este modo de ver las cosas ha quedado obsoleto y ahora se apela a un monismo en que se concibe en toda enfermedad participaciones tanto psíquicas como somáticas; sin embargo, aún la idea de «psico-somatico» expresa el viejo dualismo mente/cuerpo. ¿Cuál seria la cualidad física distintiva de la «mente» que la diferencia del resto del organismo vivo? Hacia el final de este trabajo expondré una hipótesis fundamentada al respecto. El paradigma científico vigente propone a la «mente» como el resultado del metabolismo del cerebro.

Así como se dice que el hombre es un ser bío-psico-social, las enfermedades que éste padece también comprenden estos aspectos. Quiero ofrecer disculpas por dos razones:

1. Por excluir el aspecto social, que debido a su intrincada complejidad no me es posible abordar en este breve espacio comprimido de informaciones sobre la etiología de las psicosis en sus aspectos biológico y psíquico; no obstante subrayar que lo psíquico, desde ya, supone lo social.

2. Por la aparente arbitrariedad de selección de los temas que he elegido tocar. En la primera parte me refiero a datos anatómicos, fisiológicos y biológicos de las psicosis, y en las partes subsiguientes muestro el punto de vista de los principales teóricos al 
respecto desde el psicoanálisis: Sigmund Freud, Melanie Klein, Jacques Lacan (lamento no haber podido explayarme como hubiese querido, en la parte psicoanalítica, sobre la depresión y las psicosis maniaco depresivas). Mi pretensión al realizar tan inusitada selección de temas es la siguiente: llevar a la polaridad los conocimientos adquiridos en el campo tanto de «lo objetivo» como de «lo subjetivo», por no decir más lo orgánico y lo psíquico. Lo uno, resultado de la laboriosa investigación médica, biogenética, estadística y tecnológica; y lo otro, resultado de la exploración reservada y directa acumulada a través de muchos años de experiencia clínica, y teorizada por magníficos exponentes del psicoanálisis. El psicoanálisis está al mismo tiempo dentro y fuera de la psicología, y es una de las escasísimas disciplinas que configura explicaciones que dan cuenta lógica de los fenómenos psicóticos. Sin embargo la intención final y verdadera de está revisión está señalada en la conclusión, y con ella cobra mucho sentido el resto del material precedente.

Agradezco de una manera muy especial a mis amigos Carlos Almenara, Lucía lngar y Jorge Roca -que tienen su cuota de culpa inconsciente en la aparición de este trabajo- por facilitarme información valiosa, por proporcionarme los medios para su elaboración formal, pero principalmente y ante todo, por su solidaria paciencia y amistad.

\section{Las bases neurobiológicas}

Algunas anormalidades neuroanatómicas revelan la posibilidad de una disposición biológica constitucional para la psicosis, por ejemplo, datos estadísticos recientes muestran en pacientes diagnosticados con esquizofrenia la frecuencia de anomalías en ciertas estructuras encefálicas, como ensanchamiento del sistema ventricular, alteraciones en la corteza prefrontal y temporal así como en varias zonas del sistema limbico. El tamaño relativo del ventrículo resulta ser de más del doble en muchos de estos pacientes comparados con sujetos no psicóticos, lo que demuestra la existencia de un déficit de tejido cerebral: volúmenes disminuidos de sustancia gris en el hipocampo, la amígdala y la corteza temporal. El síntoma principal de la esquizofrenia es el desorden en los pensamientos y el lenguaje, y el grado de disminución de la corteza temporal del hemisferio izquierdo se correlaciona con el grado de trastorno en el pensamiento y el lenguaje. Algunos sujetos esquizofrénicos tienen un flujo sanguíneo cerebral anormal o una anormal utilización de la glucosa en áreas específicas del cerebro. Los hallazgos de laboratorio han detectado irregularidades metabólicas de los neurotransmisores implicados en la fisiopatología de las psicosis. Los neurotransmisores son sustancias químicas segregadas por ciertas agrupaciones neuronales y actúan sobre proteínas receptoras con el fin de alterar la membrana de la neurona en la sinapsis, excitándola, inhibiéndola o modificando su sensibilidad de alguna otra manera en la propagación del impulso nervioso. Actualmente se conocen más de 100 tipos de sustancias neurotransmisoras, neuromoduladoras y receptoras. Los neurotransmisores implicados 
en la fisiopatología de las psicosis son las del tipo de las monoaminas. Las monoaminas son dopamina, norepinefrina, epinefrina y serotonina, y se sabe que la dopamina (DA) está relacionada con la esquizofrenia así como la norepinefrina (NE) y la serotonina (5HT) lo están con los trastornos afectivos, incluyendo la depresión y las psicosis maniaco depresivas.

La hipótesis de la dopamina sostiene que los síntomas positivos o visibles de la esquizofrenia son ocasionadas por una hiperactividad de las sinapsis dopamínérgicas (que contienen dopamína), principalmente en el sistema límbico, debido a la excesiva concentración de receptores para la dopamina, y cuyas causas se ignoran. Se les concede una participación especial a los receptores para la dopamina tipo D2 y D4; la densidad de los receptores a dopamina D4 se ha encontrado elevada hasta en $600 \%$, y ha sido visualizada elevada concentración de dopamina D2 en ciertas estructuras cerebrales en estos pacientes usando la tomografía por emisión de positrones (PET) -estos resultados varían en los pacientes sometidos a medicación antipsicótica-. Por ejemplo, una liberación aumentada de dopamina en el cerebro produce los síntomas característicos de la fase activa de la esquizofrenia:

a) Sensación de persecución desde fuentes externas.

b) Percepción alucinatoria de voces.

c) Habla desorganizada, incoherente o incomprensible.

d) Secuencias de pensamiento anormales y disociación de ideas.

e) En ocasiones, posturas disforzadas, rigideces o movimientos catatónicos.

Además, los medicamentos efectivos para el tratamiento de la esquizofrenia (haloperidol, cloropromacina, clozapina, olanzapina y varios neurolépticos o psicotropos atípicos) inhiben la liberación de dopamina o bloquean a sus receptores, y fármacos liberadores o agonistas de la función dopamínica como los medicamentos antiparkinsonianos, la cocaína y la anfetamina (la molécula de anfetamina se parece a la molécula de dopamina) en dosis elevadas pueden producir una psicosis tóxica muy parecida a la esquizofrenia paranoide. El incremento de la actividad dopaminérgica en la amígdala -una estructura importante del sistema límbico- está especialmente relacionado con los síndromes paranoides. En cambio, los síntomas negativos de la esquizofrenia, es decir, los registrados por defecto (aplanamiento afectivo, abulia, anhedonia, apatía, autismo, aislamiento) parecen estar relacionados con daño cerebral indicado consistentemente a través de las tomografías computarizadas (CT) y las resonancias magnéticas (MRI). Síntomas neurológicos como catatonia, detención 
del habla y de la mirada, y ausencia del reflejo de parpadeo, entre otros, observados en sujetos esquizofrénicos, están relacionados también con daño cerebral como el aumento del ventrículo y las alteraciones corticales y límbicas. La severidad de estos desórdenes está correlacionada con la severidad de los síntomas negativos de los pacientes. Algunos investigadores favorecen la hipótesis de que tales anormalidades cerebrales ocurren durante el desarrollo prenatal, en el momento del nacimiento o en algún momento después del mismo, y es posible que en ellas intervenga algún factor viral como la gripe, que es capaz de destruir neuronas en el sistema límbico y en el hipotálamo.

Detecciones tomográficas descubren anormalidades del hipotálamo y hallazgos de laboratorio arrojan también resultados que comprometen neurotransmisores y hormonas en el origen de las psicosis maniacodepresivas. La hipótesis de la monoamina sostiene que la depresión es ocasionada por una actividad insuficiente de las neuronas monoaminérgicas de los sistemas de serotonina (5-HT) y norepinefrina (NE)conocida también entre los amigos como la catecolamina noradrenalina-, mientras que su hiperactividad conduce a la manía. La reserpina, un antagonista de la serotonina y la norepinefrina demostró poder inducir a una profunda depresión. La enzima monoaminooxidasa (MAO) impide el exceso en la producción de monoaminas destruyendo la serotonina cuando su nivel es muy alto. Un descenso drástico en los niveles de serotonina debido a su destrucción por la MAO se correlaciona directamente con la depresión suicida; esta disminución es especialmente característica en los circuitos hipotalárnicos y del sistema límbico. Los tratamientos fisiológicos efectivos para la depresión consisten en la administración de medicamentos tricíclicos y tetracíclicos, inhibidores de la MAO e inhibidores de la recaptación de serotonina (que permiten mantener esta sustancia transmisora en el espacio intersináptico) como la fenfluramina o fluoxetina (prozac). Otros tratamientos indicados para la depresión son la terapia electro convulsiva (TEC) consistente en un choque eléctrico generalizado que induce a coma, y la privación del sueño que reduce y elimina transitoriamente muchas depresiones. Para las depresiones estaciónales recidivantes en invierno, se aplica la fototerapia: exposición a una luz brillante por varias horas a la semana. En el control y prevención de los estados maníacos están indicadas las sales de litio, en especial el carbonato de litio. Por todos estos motivos, entre otros, una simple hipótesis monoaminérgica de los estados maniacodepresivos no parece viable. 
Los principales métodos de investigación en genética psiquiátrica son:

a) Estudios en familias: En la población general la incidencia de la esquizofrenia es de $1 \%$ y la de la depresión de 3 a $4 \%$. El riesgo de desarrollar la enfermedad correspondiente es de 8 a $15 \%$ en familiares de primer grado de un sujeto esquizofrénico y de 10 a $15 \%$ en los de uno maníaco depresivo.

b) Estudios en gemelos: Los gemelos monocigotos son genéticamente iguales y los dicigotos o mellizos comparten un $50 \%$ de su dotación gentenica total (genoma). Si la psicosis fuera enteramente genética se esperaría que la tasa de concordancia diagnóstica en gemelos idénticos o monocigotos fuera del $100 \%$ y de $50 \%$ en los dicigotos, lo cual no ocurre. No obstante en los monocígotos la tasa de concordancia diagnóstica para la esquizofrenia es 4 veces mayor que para los dicigotos. La búsqueda de variables que expliquen las influencias de los factores medioambientales no ha dado mayores resultados, pero niveles neonatales de hormonas se correlacionan con variables de conducta medidas posteriormente. este es un factor no compartido en el ambiente uterino y una causa de variación no genética que explica las diferencias entre gemelos.

c) Estudios en sujetos dados en adopción: Muchas investigaciones muestran una frecuencia de hasta $46,3 \%$ de posibilidad de desarrollar esquizofrenia por parte de sujetos que tienen a ambos padres con este diagnóstico, a pesar de ser dados en adopción tempranamente.

d) Estudios del modo de transmisión genérica: Existen por lo menos 3 hipótesis genéticas de la esquizofrenia (dominante, recesiva y multifactorial), mientras que los desórdenes bipolares se asocian más con el cromo soma sexual X. Si la disposición biológica para la esquizofrenia constara de la transmisión de un solo gen, se esperaría observarla en por lo menos el 50\% de: los hijos de dos padres esquizofrénicos si el gen fuera dominante, pero esta formulación no se cumple en los sujetos dados en adopción. Si el supuesto gen fuera recesivo, se esperaría que todos los hijos de dos padres esquizofrénicos se convirtieran a su vez en esquizofrénicos. Sin embargo la incidencia real es menor a 50\%, lo que significa que están involucrados varios genes, y que tener un gen para la esquizofrenia imparte cierta susceptibilidad para la enfermedad, la cual estaría determinada: por otros factores. Portar un gen o más de un gen con potencialidades para la esquizofrenia no quiere decir que la persona 
necesariamente se convierta en esquizofrénica. Así como familiares cercanos de esquizofrénicos tienen mayor probabilidad de desarrollar la enfermedad, ésta también puede ser causada por factores no genéticos. Mientras la pauta biológica parece quedar impresa en la anatomía cerebral, varios estudios han encontrado que en los casos en que no existe un trastorno esquizofrénico en la historia familiar de una persona esquizofrénica, es muy probable encontrar una historia de complicaciones en o alrededor del momento de su nacimiento y dicha persona tendría también mayor probabilidad de presentar sintomatología esquizofrénica a una edad más temprana.

e) Estudios de mapeo genético: Algunos de estos estudios sugieren la probabilidad de que un gen con potencialidades maniaco-depresivas se halle en el cromosoma 11 y que otro con potencialidades esquizofrénicas se halle en el cromosoma 5. Al finalizar el año 1999 el Proyecto Genoma 2000 ha localizado con suma certeza genes para la esquizofrenia en los cromosomas 6 y 22.

Para otras enfermedades neuropsiquiátricas como el Alzheimer presenil y la corea de Huntington se tiene evidencia de sus localizaciones en los cromosomas 21 y 4 respectivamente, pero en estos casos el factor genético es determinante debido a la coincidencia de genes defectuosos en un único cromo soma. En las psicosis, como en la gran mayoría de los casos, por su distribución en varios cromosornas y su carácter poligénico, los genes sólo predicen susceptibilidad a la enfermedad mas no certeza o inexorabilidad.

Como la esquizofrenia es por lo menos parcialmente hereditaria, tiene una base biológica, pero no todos los casos son causados por la herencia y muchas personas que son portadoras de un gen para la esquizofrenia no desarrollan ni desarrollarán "necesariamente" la enfermedad. El estado de cosas actual en el campo de la tecnología genética sugiere la existencia de una multiplicidad de genes predisponentes con potencialidades psicóticas que generarían susceptibilidad a la enfermedad correspondiente. Además de la participación de los factores fisiológicos y hereditarios intervienen factores tóxicos que afectan adversamente el desarrollo o dañan el cerebro, como la exposición a ambientes contaminantes o agresivos. También el ambiente familiar, la clase social, la posición económica y variables sociales similares afectan la probabilidad de que una persona desarrolle un desorden mental y pueden dificultar o contribuir a su recuperación. Las personas con más anormalidades esquizofrénicas encefálicas pueden devenir en sintomáticas con estrés ambientales relativamente leves. Entonces la esquizofrenia surgiría cuando la combinación entre estrés y anormalidades encefálicas excede de cierto valor umbral. Incluso se ha sugerido que los factores genéticos pueden predisponer a los esquizofrénicos a presentar una plasticidad cerebral 
inusual en respuesta al «estrés habitual de la vida». Esta sugerencia deriva de numerosas observaciones que muestran que las estructuras encefálicas pueden ser modificadas por la experiencia. Hoy se sabe que algunos neurotransmisores ejercen acciones en el interior de las neuronas capaces de modificar el genoma, es decir, capaces de modificar las informaciones genéticas programadas biológicamente. Nuevas ayudas biológicas como las exploraciones con el PET (tomografía por emisión de positrones) y las técnicas genéticas pueden proporcionar una amplia identificación de los niños de alto riesgo: en un estadio precoz de la vida. las influencias biológicas y ambientales pueden reducir la posibilidad de la posterior aparición de la psicosis.

En los últimos años los estudios de imagenologia cerebral han avanzado aceleradamente; el estudio estructural del cerebro por la tomografía computarizada (CT) y la resonancia magnética nuclear (MRI) con las que se obtienen estructuras cerebrales con muy fino detalle, no son capaces de realizar estudios funcionales químicos. La tomografía por emisión de positrones (PET o positrons emission tomography) y la tomografía computarizada por emisión única de fotón (SPECT o single photon emission computed tomography) son los métodos más desarrollados para la obtención de imágenes funcionales del cerebro y facilitan el diagnóstico de las psicosis y de otros desórdenes neuropsiquiátricos. Hace pocos años un grupo de investigadores utilizando el PET estudiaron a pacientes esquizofrénicos en el momento en que tenían alucinaciones auditivas y demostraron que las áreas que se "encienden" durante estas alucinaciones incluyen núcleos subcorticales y del sistema límbico, principalmente, implicados también en la fisiopatología de los sistemas dopaminérgico, serotoninérgico y norepinefrinérgico de las psicosis, como ya lo señaláramos.

El sistema límbico es una región involucrada en las respuestas emocionales y el comportamiento. Filogenéticamente el sistema límbico se origina a partir del tronco encefálico y es un cerebro primitivo que compartimos con los reptiles y que contiene los instintos básicos de sobrevivencia. Diríase que el sistema límbico es un «cerebro emocional» y su raíz arcaica está vinculada con el sentido del olfato. Para otras especies el olor es el sentido supremo para la conservación del individuo y la perpetuación de la especie porque permite discriminar lo comestible de lo dañino, lo sexualmente accesible del enemigo y del alimento. En base a esta información el organismo sabe lo que debe hacer: morder, escupir, acercarse, huir, perseguir u optar por la decisión instantánea de si «me lo como a él o él me come a mí». Aquí la vida mental es todavía bestial y sólo sobrevive el más fuerte para transmitir sus genes. 
A partir de este rinencéfalo o «cerebro nasal» va evolucionando el cerebro hasta que en la escala humana aparece la neocorteza y el lóbulo prefrontal, residencia de la culminación de las funciones superiores y de los procesos cognitivos (inteligencia, memoria, aprendizaje, pensamiento, lenguaje, etc.). El sistema límbico funciona esencialmente para controlar nuestras expresiones emocionales y nuestro comportamiento, sin embargo la forma precisa en la que las diferentes partes del sistema límbico se coordinan para gobernar al conjunto de las funciones emocionales y del comportamiento del organismo se desconoce aún en gran medida.

Una de las partes más importantes del sistema límbico es la amígdala o cuerpo amigdalino -una de las dos partes clave del primitivo «cerebro nasal»-, poderoso centro de control de la conducta especializado en las emociones. Las interacciones primarias de asimilación psicológica del entorno quedan registradas de modo potente en la amígdala en forma de proteínas, como improntas mnésicas rudimentarias y gruesas, dado que en la escala humana son fijadas en una etapa preverbal. De esta manera no pueden ser lo suficientemente domesticadas por instancias superiores instaladas en un circuito nervioso hacia los lóbulos prefrontales, facultados para desconectar los centros emocionales pasionales y violentos, sólo compatibles con la realidad en un momento crítico de emergencia o alarma que los activa automáticamente. La lógica de esta mente es meramente asociativa y equipara la realidad externa con su propia representación de ella. En este sentido las representaciones no deben estar definidas necesariamente por su identidad objetiva sino por cómo son percibidas: las cosas son lo que parecen. Por ello puede resultar tan difícil razonar con alguien que está anímica o emocionalmente perturbado, como por ejemplo una persona que está atravesando un arrebato delirante o una aflicción extrema.

¿Los actuales alcances médicos, científicos, estadísticos y biogenéticos en torno a las psicosis, excluyen, invalidan o desmerecen su abordaje teórico desde el psicoanálisis? A la fecha, cualquier profesional de la salud concuerda con la simple formulación de que existen fuerzas y factores patógenos tanto biológicos como intr psíquicos y sociales, todos intrínsecos e indesligables uno de otro. Ya nos hemos referido a ciertos aspectos biológicos básicos para la comprensión de las psicosis, y ahora nos referiremos a aspectos patógenos de orden, digamos, «intrapsíquico». 


\section{El narcisismo}

Ya en 1914 Freud escribía: «Todas. nuestras ideas provisorias psicológicas habrán de ser adscritas alguna vez a substratos orgánicos especiales los que ejerzan acción de la sexualidad y faciliten la continuación de la vida individual en la de la especie. Por nuestra parte, atendemos también a esta posibilidad, aunque sustituyendo las materias químicas especiales por energías psíquicas especiales». También reconoció el valor de la herencia en el origen de la historia y de otras neurosis. El siguiente esquema freudiano permitirá hacerse una idea del pensamiento psicoanalítico acerca de la etiología de los trastornos mentales:

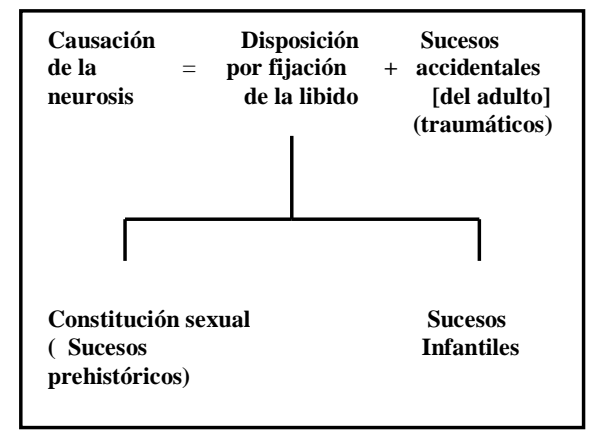

Este esquema que intenta dar cuenta de la etiología de las neurosis lo hacemos extensivo a las psicosis, a las que Freud llamaba «psiconeurosis narcisistas» para diferenciarlas de las psiconeurosis de transferencia (histeria, neurosis obsesiva) ya que advertía que un rasgo peculiar de las psicosis era su incapacidad de reportar la transferencia afectiva al terapeuta, motor primordial del proceso de curación. incluida también en esta categoría a la depresión (antiguamente denominada melancolía) y a las psicosis bipolares. Descriptivamente el narcisismo no es sino el complemento libidinoso del egoísmo del instinto de conservación inmanente a todo ser vivo. El narcisismo es el estado primario de la libido localizada en el propio yo, y que posteriormente va a destacarse en ciertas magnitudes hacia el mundo exterior con el fin de revestir objetos, transformándose así en libido objeta!. En un principio el individuo se toma a si mismo como objeto (narcisismo primario, equiparable a la fase del autoerotismo) antes de reconocer a la madre como un objeto separado y distinto de sí mismo, en cuyo caso puede tomar1a como primer objeto sexual en tanto lo erogeniza. 
La observación de la psicosis evidencia dos características especiales:

1. La cesación del interés por el mundo exterior.

2. La existencia de ideas delirantes de sobrevaloración, grandeza o autorreferencia.

El apartamiento de los objetos y de los vínculos sociales implica la retracción del enfermo de la carga de libido que les había destacado (catexia), y así todo ha llegado a serle indiferente y ajeno, teniendo que ser explicado por medio de una consecutiva racionalización. Las experiencias de «transformación cósmica», extrañamiento de la realidad o «fin del mundo» que vivencia el esquizofrénico como proceso de la fase activa inaugural de los síntomas positivos de la afección, es la proyección en el exterior de este colapso interno: su universo subjetivo se ha trastocado desde que él le ha retirado su interés real. Vuelve, luego, a reconstruirlo pero profundamente alterado; lo reconstituye con la labor de su delirio. El delirio en el cual vemos el producto de la enfermedad es en realidad la tentativa de reconstrucción, necesariamente de modo incompleto e insuficiente. El proceso de retracción de la libido es silencioso, mientras que el de procura de restablecimiento se hace advertir ruidosamente a través de los delirios, las alucinaciones tormentosas y la desorganización del lenguaje y el comportamiento. La libido se recanaliza del cauce alterado que significó la atracción narcisista concéntrica y retorna, pero trastornada y con carga de signo negativo, o sea de hostilidad, persecución, daño, invasión, manipulación, etc. «Lo interiormente rechazado (Verwerfung) retorna desde el exterior».

Podría decirse, también, que el narcisismo es una etapa intermedia entre el autoerotismo y el amor objetal. La elección de objeto anula al autoerotismo.

Las pulsiones sexuales entregadas a una actividad autosatisfactoria o autoerótica, para llegar a un objeto amoroso, toman en un principio al propio cuerpo como objeto sexual antes de acceder a uno otro como tal. En el propio cuerpo elegido así como objeto pueden ser ya los genitales un elemento principal, desarrollándose a la par una elección homosexual de objeto cuyo curso influenciará la heterosexualidad convencional efectiva a la postre. La homosexualidad es una manifestación narcisista, pues busca su objeto conforme al modelo del propio yo. Para el psicoanálisis la falta de toda relación de dependencia entre el sexo del individuo y su elección de objeto, y la posibilidad de orientar indistintamente esta última hacia objetos masculinos o femeninos, conforma la actitud primaria original, a partir de la cual se desarrolla luego el tipo heterosexual o el invertido (bisexualidad primaria).

Se propuso la existencia de una inclinación homosexual latente en las psicosis, esencialmente en la paranoia, entre otras razones, porque se confirmaba en todos los casos que el último eslabón en la cadena de los perseguidores o de los referidos a la convicción delirante del paranoico, lo constituía siempre una persona del propio sexo, la 
cual muchas veces suscitaba, previo al delirio, sentimientos cariñosos. La proyección es un mecanismo del que se vale el paranoico eminentemente, y consiste en imputar a otro la propia tendencia, o en eximirse de ésta, atribuyéndola al exterior a manera de percepción exógena y en la que juega el yo un rol pasivo, sustrayéndose de la consciencia el influjo de las tensiones internas. La declaración homosexual es negada de facto por la censura, luego es invertida en su contenido o desviada de persona por proyección, y luego, si aún no puede ser acogida por la consciencia en su forma deformada, procede el mecanismo de la racionalización (las «declaraciones» son obviamente extensivas a las mujeres):

\section{Delirio de persecución:}

Tendencia homosexual: «Yo (un hombre) lo amo»

Negación e inversión del contenido (del verbo): «No. Yo no lo amo, lo odio»

Proyección: «No lo odio, él me odia a mí»Racionalización: «Por eso me persigue» (construcciones e interpretaciones delirantes) «lo odio porque me persigue»

\section{Delirio erotomaníaco:}

Tendencia homosexual: «Yo (un hombre) lo amo»

Negación y desvío de la persona (el sujeto): «No. Yo no lo amo a él, la amo a ella»

Proyección: «Es ella quien me ama» Racionalización: «Luego, puedo yo amarla también» (construcciones e interpretaciones delirantes)

\section{Delirio celotípico:}

\section{- Celotipia alcohólica}

Tendencia homosexual: «Yo (un hombre) los amo (compañeros solidarios en la bebida)» Negación y proyección: «No soy yo quien ama a los hombres, es ella quien los ama» (celos delirantes)

- Celotipia femenina

Tendencia homosexual: «Yo (una mujer) la amo»

Negación y proyección: «No soy yo quien la ama, es él» (objeto femenino identificado de inclinación homosexual)

Delirio de grandiosidad o megalómano (también en la manía): 
Tendencia homosexual: «Yo (un hombre) lo amo»

Negación y fundamento delirante: «No. Yo no amo a nadie, sólo me amo a mí mismo» (construcciones delirantes)

La última frase no requiere siquiera de la proyección sino de la simple recaptación narcisista. A pesar de ser evidente la importancia de la latencia homosexual atribuida a la psicosis, ésta tiene un papel muy importante también en las neurosis. En la psicosis el conflicto se establece entre el yo y el mundo exterior.

El yo se torna dependiente del Ello (acervo de contenidos inconscientes reprimidos individuales y ancestrales de la especie) retirándose de una parte de la realidad. Tanto la neurosis como la psicosis son expresión de la rebeldía del Ello contra el mundo exterior o de su incapacidad para adaptarse a la realidad, sólo que la neurosis no la niega, limitándose sólo a no querer saber nada de ella; en cambio la psicosis la niega e intenta sustituirla por otra. Así pues, la psicosis demuestra una adhesión al Ello o a las pulsiones primitivas y contenidos desiderativos que lo integran, mientras que la neurosis aún propende hacia el mundo exterior, sometiéndose a sus requerimientos. Una diferencia fundamental entre neurosis y psicosis es que en la primera la carga de libido o catexia ha sido retraída a la fantasía o al objeto de la fantasía, mientras que en la psicosis esta carga o interés sexual recae sobre el propio yo, perdiendo así el contacto con la realidad. Respecto a la distinción entre neurosis y psicosis, cabe contemplar la distribución paralela de dos pasos análogos:

\section{Neurosis:}

a) La represión de la exigencia censurable del Ello (sexual, destructiva).

b) El retorno de la misma bajo una forma desfigurada (síntomas).

\section{Psicosis:}

a) El apartamiento de la realidad (retracción narcisística).

b) Los intentos de recuperar la realidad perdida (delirio y desorganización).

Los procesos asociativos en la psicosis se rigen por los mecanismos de condensación y desplazamiento propios de la articulación de los sueños conforme a un proceso primario dado también en una fase temprana de la vida, y dominado por el principio del placer, consistente en la tendencia del organismo a evitar los estímulos displacientes y a conseguir una satisfacción inmediata. Dicha satisfacción conllevaría al organismo, en última instancia, a retornar a un estado inactivo e inerte original que precedió su insurgencia en la vida (la pulsión de muerte). Lo que ha quedado profundamente alterado en el psicótico es un dispositivo del yo encargado de efectuar una evaluación o examen de la realidad que le permita discriminar las percepciones reales de las imaginarias. En un comienzo el organismo es embargado por sensaciones que no puede eludir y cuya única reacción refleja de inervación somática es una descarga en 
llanto y pataleo. Al no estar formado el dispositivo que permite distinguir la realidad, se plantea en el bebé en procura de alivio, una alucinación desiderativa para neutralizar las sensaciones displacientes. Si la alucinación (vivencia de satisfacción del inefable pecho materno y de los estímulos placientes) lleva a la realización del acto reflejo correspondiente(la succión), su consecuencia ineludible será la defraudación. Para la primera infancia no existe «realidad»; una ulterior «pérdida de la realidad» representa una regresión a esa temprana época. El yo regresa a su primitivo estado indiferenciado fusionándose con el mundo (desrrealización) y disolviéndose total o parcialmente en el Ello sometido al proceso primario del principio del placer desconectado de la realidad. La sexualización de las relaciones sociales anula las sublimaciones logradas en el transcurso de la evolución. Consta así que, para el psicoanálisis los delirios psicóticos son fantasías de género inconsciente que se han hecho inmediatamente conscientes: lo inconsciente es consciente en la psicosis.

\section{La posición esquizo-paranoide}

Melanie Klein adjudicó a la. actividad de las fantasías un desempeño preponderante durante las primeras experiencias vitales. La fantasía inconsciente es una expresión mental de los instintos o pulsiones, y por consiguiente, existe como éstos desde el comienzo de la vida. El aparato psíquico relaciona el instinto con la fantasía de un objeto adecuado a él de modo que, para cada impulso instintivo hay una fantasía correspondiente. Por ejemplo, el bebé somnoliento que mueve la boca con expresión placentera y hace ruidos de succión o se chupa los dedos, fantasea que está realmente succionando o incorporando el pecho, y se duerme con la fantasía de tener el-pecho-que-da-leche realmente dentro de sí. En forma similar, el bebé hambriento, furioso, que grita y patalea, fantasea que está realmente atacando al pecho, desgarrándolo y destruyendolo, y vivencia sus propios gritos que lo desgarran y lastiman como el pecho desgarrado atacándolo en su propio interior. Cuando el sujeto proyecta una alucinación desiderativa o fantasía de realización de deseos en un estado de privación, está evitando la frustración de una realidad externa displaciente pero también se esta defendiendo contra la realidad de su propia hambre y de su propia ira, o sea, contra su realidad interna. El concepto freudiano de realización alucinatoria de deseos implica un yo capaz de establecer una relación objetal en la fantasía. En las primeras etapas del desarrollo el yo es lábil, se halla en constante fluencia, su grado de integración varía de día en día y hasta de un momento a otro; aquí el yo está expuesto a la innata polaridad y conflicto de las pulsiones de vida y muerte; el yo deflexiona la pulsión de muerte y el miedo original a ésta se transforma en miedo a un perseguidor. La intrusión de la pulsión de muerte se siente objetivada en el pecho escindiéndolo en muchos pedazos, de manera que el yo se encuentra a merced de multitud de perseguidores. El niño experimenta estados atribulados de ansiedad relacionados con sentimientos de frustración e impulsos de muerte, los cuales generan miedo a la propia aniquilación y son causa de 
ansiedades persecutorias. El superyó (instancia psíquica censora y prohibitiva que es presentida al transgredirla como sentimiento de culpa) aparece entre los 2 y 4 meses aproximadamente, iniciándose con las primeras introyecciones orales (la introyección es un mecanismo que busca, en la medida de lo posible, internalizar todo lo bueno del exterior, y es el par antitético de la proyección que intenta externalizar lo malo del interior y objetivarlo). En la posición esquizo-paranoide (O a 3 ó 4 meses aprox.) la ansiedad predominante es paranoide y el estado del yo y de sus objetos se caracteriza por la desintegración y la escisión que son esquizoides.

El «pecho malo»o frustador es odiado y adquiere cualidades oralmente destructivas. En sus fantasías el niño muerde y ataca al pecho y siente que el pecho lo va a atacar en la misma forma por proyección. La expulsión de las heces simboliza un enérgico rechazo del objeto incorporado y va acompañada de sentimientos de destrucción. A medida que los impulsos uretrales y sádico-anales progresan, el niño ataca al pecho con orina y excrementos; luego siente que el pechó puede ser explosivo y venenoso para él, erigiéndose ideas persecutorias y devastadoras del pecho malo vengativo. La introyección de los objetos malos persecutorios es hasta cierto punto determinada por la proyección de impulsos destructores y malevolentes sobre el objeto. El deseo de proyectar maldad aumenta por el temor a los «perseguidores internos». La ansiedad es la responsable del incremento de los impulsos a destruir objetos externos. Los sentimientos persecutorios aumentan aún más las ideas del «pecho bueno» en el deseo de que el pecho sea un refugio ante ellos. El periodo de fijación o clivaje de la esquizofrenia es en este momento de inmenso sadismo: la división del pecho en bueno y malo da origen a la sensación de que el yo está también disociado. El sadismo oral alcanza su nivel máximo durante e inmediatamente después del destete. Las ganas de chupar y morder dirigidas al pecho se extienden al interior del cuerpo de la madre que contiene más objetos parciales malos. «En los primeros meses de la existencia del niño, éste tiene impulsos sádicos dirigidos no sólo contra el pecho de su madre, sino también contra el interior de su cuerpo; impulsos de vaciar su contenido, de devorarlo y destruirlo por todos los medios que el sadismo puede sugerir» (M. Klein, 1934). La proyección hacia afuera de malos sentimientos y partes malas del yo produce persecución externa. La reintroyección de perseguidores origina ansiedad hipocondríaca. La proyección hacia afuera de partes buenas produce la ansiedad de quedar vacío de bondad e invadido por enemigos perseguidores. Para protegerse, el yo opta por el más desesperado de los intentos: la desintegración, hacerse pedazos y quedar pulverizado. La ansiedad no es sino la respuesta del yo a la actividad del instinto de muerte; ésta puede ser paranoide o depresiva. 
El buen desarrollo del bebé durante la posición esquizo-paranoide va a depender de que las experiencias buenas predominen sobre las malas. Las experiencias del bebé van a depender de factores internos y externos. La gratificación que proporciona el ambiente puede alterarse por factores internos hasta llegar a impedir tal gratificación. En esto intervienen tres emociones o impulsos básicos: la envidia, los celos y la voracidad. La envidia es la más elemental de estas emociones fundantes; es una relación de dos partes en que el sujeto odia al objeto por alguna posesión o cualidad. La envidia se experimenta fundamentalmente en función de objetos parciales (pecho, pene), aunque persista en relaciones de objetos totales (madre, padre) vistos como parciales, mientras que los celos implican una relación de objeto total. El objetivo de la voracidad es poseer todo lo bueno que pueda extraerse del objeto, pero la destrucción del objeto es contingente y no el fin. El fin es adquirir lo bueno a toda costa, estando, no obstante, impregnado de un vampírico instinto de muerte. Al atentar contra la propia fuente de vida y de amor, se la puede considerar como la primera externalización de la pulsión de muerte.

El alimento percibido como habiendo formado parte del pecho, es en sí mismo destino de arremetidas envidiosas. La envidia utiliza la proyección -con frecuencia su mecanismo favorito-, por ejemplo cuando el bebé se siente repleto de ansiedad y de maldad, y siente que el pecho de la madre es una fuente de todo lo bueno, por envidia quiere estropear el pecho proyectándole partes malas y dañinas de sí mismo: en su fantasía lo ataca escupiéndole, orinándolo y defecándolo, con flatos y con la mirada penetrante proyectiva (el «mal de ojo»).

A medida que se prosigue el desarrollo, continúan estos ataques dirigidos ahora contra el cuerpo entero de la madre (objeto total) y la relación coital de los padres (los celos). La envidia se puede fusionar con la voracidad, constituyendo así otro determinante del deseo de extinguir completamente al objeto, no sólo ya para poseer todo lo bueno, sino también para exprimirlo y destrozarlo a fin de que ya no contenga nada envidiable. Al atacar y arruinar al objeto bueno -que origina envidia- no se puede mantener el proceso de escisión en un objeto bueno y en uno malo persecutorio que es de capital importancia durante la posición esquizoparanoide. Un objeto «ideal» es aquel objeto perfecto y carente de toda maldad, siendo por esto mismo un objeto idealizado e inalcanzable fijado como fantasía contra los objetos malos y «extraños». Pero este recurso ha convertido a este objeto ideal en un verdadero encubridor de objetos parciales sumamente destructivos y persecutorios, quizás los más peligrosos de todos. 
Las defensas paranoides van a conducir a una confusión entre lo «bueno» y lo «malo» que interfiere en la escisión y va a impedir preservar al objeto bueno y la identificación con él, por lo tanto el desarrollo del yo debe sufrir necesariamente. Cuando la envidia es muy intensa lleva a la desesperación. Al no encontrar objetos buenos no hay esperanza de recibir amor y ayuda: los objetos arruinados y despedazados provocan incesante persecución y luego culpa durante la posición depresiva.

Si estas experiencias malas superan a las buenas, se planteará un devenir patológico donde la realidad se vivencia en esencia como persecución. Se odia con vehemencia toda experiencia interna o externa. Cada diminuto pedazo en que ha sido fragmentado el objeto se convierte en una fracción violentamente hostil del yo u «objeto extraño». El bebé esquizoide vive en un mundo muy distinto ya al del niño normal, con quien compartía en un principio las mismas experiencias malas. Tiene su aparato perceptual dañado, se siente rodeado de objetos proyectados caníbales y voraces (los «objetos extraños»), sus vínculos con la realidad están cortados o son muy dolorosos, y su capacidad de establecerlos y de integrarse se ha desbaratado.

La posición depresiva es un concepto de importancia suprema en la teoría de Melanie Klein y corresponde a una etapa posterior de ansiedad depresiva que oscila entre el tercer y sexto mes, y aún después, incluso hasta el final del primer año. Aquí el bebé puede distinguir objetos totales (personas), y crece su poder para expresar emociones. Su ansiedad depresiva está referida al miedo de perder al objeto amado y la motiva la posibilidad de que la propia agresión aniquile o haya aniquilado para siempre al objeto, siendo ésta la primera experiencia depresiva que padece todo ser humano. El amor, el odio, lo bueno, lo malo, se enlazan ahora a personas enteras. El temor de perder al objeto amado por haberlo oprobiado y estropeado ocasiona ansiedad depresiva y ésta a su vez aumenta la avidez. La ansiedad de sentir a la madre expuesta al peligro de ser aniquilada o desaparecida para siempre conduce al infante a una fuerte identificación a fin de asegurarse la permanencia interna del objeto envilecido y fulminado por su odio. Como en esta etapa surgen sentimientos de congoja, culpabilidad y arrepentimiento muy intensos, aparecen los impulsos de reparar al presunto objeto injuriado y agotado del abastecimiento nutricio. Los padres ambivalentemente amados durante la posición depresiva forman el núcleo del superyó. El niño debe identificarse con el objeto comiéndoselo para conjurar la maldad y la venganza.

En la cúspide de la ambivalencia puede sobrevenirle la desesperación depresiva al recordar que ha amado, y que en realidad ama aún a su madre -la madre buena-, pero siente que ha atentado contra ella, que ya no la merece y que por tanto ha quedado desamparado y condenado. El conflicto depresivo es una lucha constante entre la destructividad del bebé y sus impulsos eróticos y reparatorios. El bebé cree omnipotentes sus impulsos tanto buenos corno malos. Las defensas maníacas contra la ansiedad depresiva se dan ante la sensación de haber perpetrado una atrocidad contra la madre en 
virtud de ser una «madre mala». Este es uno de los mecanismos ejercitados por el bebé durante la posición depresiva de odio. La negación de los sentimientos depresivos se puede conseguir temporalmente triunfando sobre ellos; esto está ligado a la derrota del objeto durante el primer ataque infligido por la retaliación depresiva. Este sentimiento de triunfo omnipotente coadyuva a no permitir que afloren los sentimientos de dependencia depresivos, que se evitarán, negarán o invertirán. El desprecio es una manera de negar la valoración del objeto, y por ende los sentimientos de pérdida y culpa. Más aún, es motivo para seguir ensañándose con él por envidia. En otro sentido, la realidad procura restaurar al objeto bueno internalizado amado y dañado. Dicha reparación puede usarse como parte del sistema de defensas maníacas, en cuyo caso adquiere las características maníacas de control, manipulación, negación y desprecio.

El punto de fijación o clivaje de las enfermedades psicóticas yace en la posición esquizo-paranoide y en los comienzos de la posición depresiva. Cuando se produce una regresión a estos puntos tempranos del desarrollo, el sentido de la realidad se enajena y el individuo se psicotiza. Pero si se alcanzó la posición depresiva y se la elaboró por lo menos en parte, las dificultades que aparecen en el desarrollo posterior no son de carácter psicótico, sino neurótico. En este punto se puede advertir la génesis de la formación de símbolos. Al comienzo de la posición depresiva el superyó es vivenciado aún como muy severo y persecutorio -la madre o padre malos-, luego los impulsos reparatorios destinados a recomponer y restaurar los objetos buenos prefiguran las bases de la confianza, la creatividad, la sublimación y el amor futuro. Sólo a través de un proceso de duelo, culpa y nostalgia puede producirse una renuncia y expiación exitosas. La formación de símbolos resulta ser la consecuencia de una pérdida. La posición depresiva nunca se elabora completamente. Siempre tenemos ansiedades relacionadas con la ambivalencia y la culpa, y situaciones que reavivan experiencias depresivas de remordimiento («re-morder»). 


\section{La forclusión del Nombre-del- Padre}

Como preámbulo de una de sus obras más importantes" Jacques Lacan enuncia: «En particular, no habrá que olvidar que la separación en embriología, anatomía, fisiología, psicología, sociología, clínica, no existe en la naturaleza y que no hay más que una disciplina: la neurobiología a la que la observación nos obliga añadir el epíteto de humana en lo que nos concierne». Parece ser que, en efecto, la naturaleza humana es de lo más antinatural que hay. Dentro de la evolución de los repertorios operativos específicos del hombre, el lenguaje simbólico es un acontecimiento único en la biósfera. Desde el lenguaje, cabe referimos al significante como esencia de la materialización del inconsciente lacaniano; se dice que el inconsciente está estructurado como un lenguaje. Así también, a decir de Lacan, el drama de la locura se situaría en la relación del hombre con el significante. El psicótico se halla congelado en una línea de relación binaria donde no hay acuerdo concertado o pacto que gobierne las diatribas de la experiencia sensorial. «En el lugar donde el objeto indecible es rechazado en lo real, se deja oír una palabra», pues ocupa el lugar de lo que no tiene nombre; la irrealización no está toda en el símbolo ya que repentinamente irrumpe en lo real. Es en lo real donde experiencia el psicótico; en un real inminente, directo y encarnizado, irreconciliado con los entramados de un orden simbólico transigente en la concesión, un referente capital en la contextualización del lenguaje aún allí en su mínima expresión atómica: el significante.

Un signo lingüístico, como entidad significativa aislada tiene la propiedad, no de unir una cosa con un nombre, por ejemplo, la palabra «gaviota» con el ave marina, sino de un concepto interno con una imagen acústica, de manera tal que ambas representaciones son cognitivas. El signo es la combinación del concepto y de la imagen acústica en una correspondencia recíproca cerrada, según Saussure. El significado vendría a ser la cosa en sí y por si, porque es; mientras el significante, la mera nominación que se da a la cosa («gaviota», «mouette», «seagull», «gabbíano», «Möwe», etc.). Su representación además de ser física por las vibraciones sonoras emitidas en su enunciación, trasciende la contingencia reservándose la plaza de una genuina huella psíquica. La asignación de un significante determinado a un significado se sostiene en un artificio arbitraría, obra de la convención lingüística; es decir, no hay nada en la palabra o fonación de «g-a-v-i-o-t-a» que nos sugiera a lo que esta referido y, a la inversa, no hay nada en la cosa que nos recuerde a la palabra per se. Se trata, simplemente de una sucesión de sonidos o fonemas que en base a un código de unidades diacrónicas dan lugar a la combinación y formación de otras mas complejas continentes de significación. Saussure dice: «En efecto, todo medio de expresión recibido de una sociedad se apoya en principio en un habito colectivo o, lo que viene a ser lo mismo, en la convención ( ... ) Se ha utilizado la palabra símbolo para designar el signo lingüístico o, más exactamente, lo que nosotros llamamos el significante. Pero hay inconvenientes para admitirlo como tal a causa de nuestro primer principio [de arbitrariedad]. El símbolo tiene por carácter no ser nunca completamente arbitrario; no está vació: siempre hay un vínculo natural entre 
significante y significado». Lacan disuelve está correspondencia biunívoca de relación entre significado y significante, confiriéndole al significante un estatuto de categoría polisémica y multívoca, independiente y fundamental.

Son propuestas tres dimensiones subjetivas para idear el concierto de la identidad y existencia humanas. El sujeto está integrado de un registro simbólico, un registro imaginario y uno real activados siempre en sincronía. La dimensión simbólica introduce la ley y la convención que estatuyen los pactos rectores de las coordenadas sintagmáticas y paradigmáticas, donde las cosas tienen nombre y pueden ser evocadas. La dimensión imaginaria entraña la imagen y su poder cautivante de encantamiento y embeleso; ¿qué es lo que esconde tanto la belleza de las imágenes que extasía y paraliza? Pues que ellas mismas -las imágenes- son huecas y sólo aparecen para obturar su propia evanescencia. Un plano imaginario emparenta toda relación intersubjetiva con una posición de exclusión disyuntiva o bien fusión, siendo sin más alternativa, una relación mortífera signada por la pulsión de muerte. Lo real es lo imposible; aquello inefable e inaprensible que queda como esto de lo simbólico, no sometido a ningún acuerdo y cuya trascendencia excede la cognición o no es reductible a sus circunscripciones. Si tomamos lo real como el percepto avasallador en la delusión psicótica, se presta la simbolización como tentativa de adscribirle algún sentido, si bien desfasado y operativo por hipercompensación del agujero en su estructura.

El estadio del espejo consagra la apertura del sistema imaginario y da cuenta del narcisismo primario, donde el bebé no posee aún una noción unificada de su cuerpo. La formalización del yo se funda en la identificación del niño con una Gestalt que lo forma, pero que lo aliena primordialmente haciéndolo «otro» (a'). El estadio del espejo transcurre entre los seis y los dieciocho meses y consiste en una identificación a la imago materna (identificación primaria). La inserción en el plano imaginario tiene cabida a razón de la propia prematuración humana del nacimiento, que trae la vida en un estado de completa indefensión y de inmadurez del sistema nervioso (fetalización): aún no hay mielinización del sistema piramidal -tracto corticoespinal- cuyos haces transportan señales que controlan la acción muscular; cuando se mieliniza la corteza y ya pueden reconocerse imágenes, todavía no puede coordinarse la motiliciad. La «cría de hombre» antes de la palabra, se diferencia del chimpancé de igual edad que aquí lo va superando en inteligencia instrumental, en que ya es capaz de reconocer su imagen en el espejo como propia, vivenciándola gozosamente. El niño sostenido por la madre reconoce su imagen en el espejo con gran algarabía, logrando una anticipación imaginaria de la forma total de su cuerpo que es percibido, vía propioceptiva, como fragmentado y disgregado, precipitándose a una transformación compositora que revoca la imagen asumiéndola corno propia. La indefensión vuelca al niño a una anticipación de su forma total, activada a partir de la amenaza de fragmentación dada por la fascinación y deslumbramiento de la imagen que es objeto de una libido «eroto-agresiva»: los celos primordiales que buscan desmembrar y dislocar al otro (el semejante) en respuesta a su completud e 
indestructividad. La agresividad constitutiva del ser humano debe ganar su lugar sobre el otro que lo enajena y lo aliena con su imagen, e imponérsele suplantándolo a riesgo de ser él mismo aniquilado. Toma la forma como propia y formaliza los futuros objetos de su deseo según se refiera el deseo del otro, sujeto como él, del lenguaje. «El inconsciente es el deseo del Otro». Este Otro (Autre) es el lugar donde el inconsciente está estructurado como un lenguaje; tesoro de los significantes.

La relación imaginaria es el espejismo narcisista en su contacto plenamente ambivalente con el objeto primordial, aquella matriz que sacia, colma y devora proyectivamente. La identificación primaria prefigura toda relación al borde de lo mortifero. Esta relación forja un plano introyectivo/ proyectivo que es el primer «campo de la realidad»; la imagen especular es el complemento narcisista o significante del objeto primordial: la Madre. El yo es aquí erigido por su contraparte imaginaria en ideal del yo: «el niño en cuanto deseado». El vector del inconsciente dirigido hacia el sujeto (S) significatizado como falo imaginario, ha de ser escindido o castrado desde el lugar del Otro, baluarte de la palabra, por el significante Nombre-delPadre.

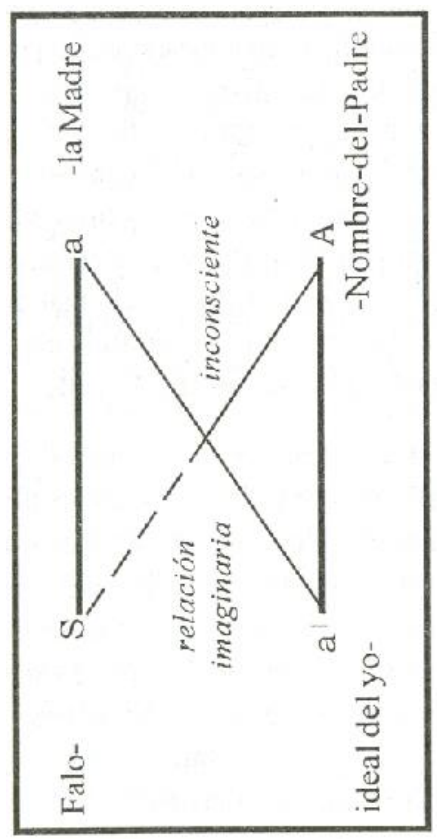

La identificación con la Madre se concreta siendo el yo significatizado como Falo. La exigencia de una madre es proveerse de un falo imaginario, siendo el hijo el soporte de esa prolongación imaginaria. La función imaginaria del Falo es el punto de apoyo del proceso de diferenciación anátomica de los sexos en el plano simbólico, llevado a cabo por el complejo de castración, que en la mujer se juega por la envidia del pene no habido, anhelando en su lugar un niño del padre.

El complejo de Edipo puede diseccionarse en base a tres momentos trascendentales:

1) La identificación con el otro como imagen propia durante el estadio del espejo 
(identificación primaria a la imago materna).

2) Irrupción de una terceridad que impide y hace retroceder las tendencias convergentes de cristalización narcisista de ambos entes (Madreniño) instituida por la «prohibición del Padre» como autoridad y ley, y su instrumento, la castración imaginaria.

3) El sometimiento al orden que permite el acceso a la organización simbólica a través del Nombre-del-Padre. Acerca del Nombre-del-Padre, Lacan dice: «la atribución de la procreación al padre no puede ser efecto sino de un puro significante, de un reconocimiento no del padre real, sino de lo que la religión nos ha enseñado a invocar como el Nombre-del Padre». Lo que está en juego en el Edipo no es un triángulo padre-madre-hijo, sino un triángulo (padre)-falo-madre-hijo, en cuanto es el Padre el agente magnético que oblitera la colisión imaginaria.

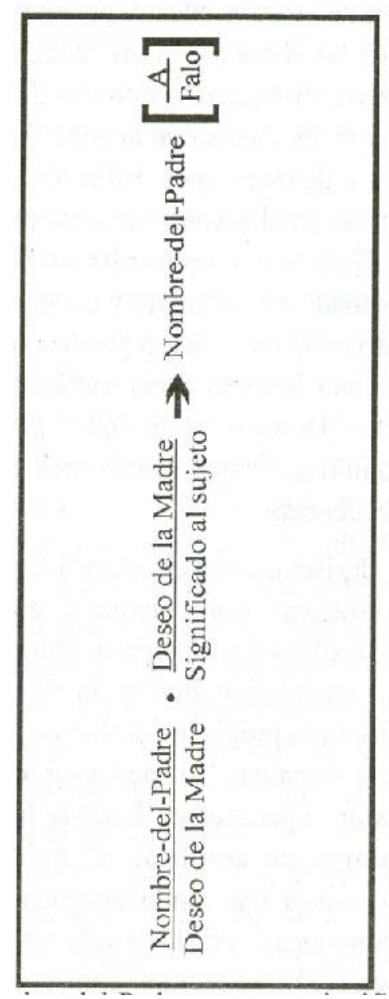

El deseo fálico de la Madre de hacer del niño una prolongación suya es intervenido por el Nombre-del-Padre como significante normativo. En esta operación se anulan ambos «Deseo de la Madre» y el Nombre-del-Padre otorga un significado legitimador al 
sujeto. El Falo es un significado inducido por la metáfora lógica en el otro (a). El significante detenta una posición privilegiada en el otro como impartidor de la anuencia al pasaje simbólico. El psicótico está «fuera del discurso», puesto que no ha accedido a la directriz simbólica instituida por la metáfora paterna.

En la psicosis «lo interiormente rechazado (Verwerfung) retorna desde el exterior». Lacan traduce esta Verwerfung (rechazo, exclusión, repudio) por forclusion, que en francés equivale a «el vencimiento de una facultad o derecho legislativo no ejercitado en los plazos prescritos». La forclusión es un defecto que da a la psicosis su condición estructural esencial que la diferencia de la neurosis, y que implica que aquello que ha sido repudiado ya no puede volver al lugar mismo del que ha sido excluido: Un accidente en el registro del Otro en cuanto ámbito del inconsciente, cumplido en la forclusión del Nombre-del-Padre, fracaso de la metáfora paterna, y queda estructurado el germen de la condición psicótica, donde Ello habla.

La entrada en la psicosis se despliega en el campo imaginario, en relación con el corto circuito afectivo que hace del otro un ser de puro goce y de pura interdestrucción. En este momento, desde el lugar del Otro es invocado un significante inconcebible cuyo desencuentro hace despegar el cataclismo imaginario, la disociación y fragmentación de los objetos, el cuerpo desmembrado, el neologismo superdeterminado, el estribillo ecolálico mecánico y vacío, la descomposición del discurso interior. El sujeto es tomado por lo real.

Como sabemos, es de obligatoriedad un requerimiento exógeno, un llamamiento a la vida que posibilite la supervivencia del individuo en la especie humana. Tal requerimiento no tiene que ser, como también sabemos, de todas maneras delegado a la madre biológica, sino a la Madre. De igual forma, al hablar del Nombre-del-Padre, se trata de un Un padre situado en posición tercera, que vele por la sujeción a la ley que dicta los parámetros de la relación con la Madre establecida en un margen al borde del incesto prohibido. La Madre, en tanto madre fálica en su relación filial, ha de avenirse a un Un-padre y reservarle un lugar de promoción de la ley, para liquidar la unión narcisística inconcretable al vástago. Caso contrario habría de producirse la muerte del sujeto y la estructuración psicótica. El sujeto (S) ha de ser escindido en sujeto del inconsciente (S) por el Nombre-del-Padre para poder sujetarse al orden simbólico estructurante, una vez instaurado el dominio de la represión que atesora los contrapuntos significantes y que permite la existencia subjetiva. En la psicosis hay forclusión del Nombre-del-Padre y ha tenido lugar una regresión tópica al estadio del espejo, por cuanto la relación con el otro especular se reduce a su filo mortal.

\section{Conclusión}

La mayor parte de la actividad del sistema nervioso es iniciada por reacciones 
sensitivas emanadas de receptores sensitivos, ya sean receptores visuales, auditivos, táctiles sobre la superficie del cuerpo o de otros tipos. Estas reacciones sensitivas pueden causar una experiencia inmediata o su recuerdo puede ser almacenado en el cerebro por minutos, semanas o años, y luego puede ayudar a determinar la experiencia somática en el futuro. Hemos visto que para el psicoanálisis estas reacciones tienen consecuencias.

Existen, como es obvio, diferencias comparativas fundamentales entre la escala zoológica y la humana. Entre tantas otras, entendemos que el animal no se aliena con su propia imagen como lo hace la «cría humana». No hace mucho se han realizado experimentos donde se liberaba dopamina en cerebros de animales, observándose una conducta agresiva y de" huida análoga a la de los «sentimientos de persecución externa» conocidos en enfermos psicóticos. ¿Podríamos caer por un instante en la ridícula interpretación de que el animal «se psicotiza»? Seguramente si, en el caso de que perciba voces que le hacen mofa y lo insultan, de que se sienta el elegido de Dios para cumplir una misión redentora del mundo, o de que profiera neologismos o palabras estereotipadas. El hombre es un animal de lenguaje y de ahí que su universo subjetivo esté completamente organizado (o desorganizado) en función de sus símbolos. Un tratamiento posible de la psicosis por el psicoanálisis se orientaría en pos de procurar que el sujeto significatice una parte de su realidad interna obturada por la forclusión de un significante fundamental, o procurar significatizar tal significante en pro de una suplencia de significación; o bien, encaminarlo hacia la traslación a una posición depresiva que le permita elaborar la violencia de los objetos malos introyectados y proyectados que le producen las sensaciones de fragmentación y persecución, a fin de hacerse responsable por estos objetos y expiarlos. Claro que esto no es suficiente. La psiquiatría estima esenciales tanto la farmacoterapia como las campañas de educación y prevención familiar, y las psicoterapias. El psicoanálisis se inscribe en este último registro. Ha sido un error generalizado la creencia de que las psicosis tienen un curso de deterioro irreversible e irremisible. No es una novedad para la psiquiatría actual el hecho de que más del 50\% de quienes sufren esquizofrenia se recuperan o mejoran significativamente a través de los años si siguen el tratamiento correspondiente por el plazo necesario.

El proceso enormemente complejo del metabolismo cerebral está dado por la constitución genética individual que es a su vez modelada por la experiencia subjetiva estructurante; Ortega y Gasset diría: «yo soy yo y mi circunstancia». Al pasar del tiempo iremos contando de seguro con instrumentos cada vez más eficaces para identificar factores genéticos potencialmente patógenos que permitan discernir mejor la etiología de las enfermedades en general. Actualmente ya contamos con muchos. Y bien que podamos manipular y modificar los genes a nuestro antojo, ¿no intentaremos erradicar por este medio factores patógenos potenciales con la finalidad de precaver a nuestros semejantes de la posibilidad del sufrimiento que trae consigo la enfermedad?, y todavía, ¿no buscaremos librar a nuestra especie de «taras», haciendo del hombre un ser más fuerte y vigoroso, encarnación ideal de nuestras ilusiones de perfección? Desde luego, no 
serán invocados aquí preceptos éticos, filosóficos o religiosos para justificar una negativa, sino que simplemente remitiré la reflexión a la naturaleza como expresión de la biodiversidad que ampara la ya muy precaria estabilidad de nuestro ecosistema del que depende a su vez toda vida. Pero tampoco soy un ecologista. ¿De qué sociedad de personas «normales» o «sanas» habrían surgido personalidades corno Nietzsche, Van Gogh o Tchaikovski -por nombrar sólo a tres- cuyos aportes a la cultura y el arte de la civilización son invaluables? Tal vez no de una sociedad homogeneizada. La mayor riqueza del hombre (puede que la única) reside en su variabilidad y diversidad de posibilidades culturales.

Otra tentación por la que nos sentimos seducidos a menudo, consiste en la legítima aspiración de demarcar discretamente el ámbito de aquello admitido como «normal»o «sano». Es muy posible que tal como ocurre en la medicina «somática», las enfermedades mentales . puedan ser conceptualizadas según un criterio de rango de desequilibrio orgánico, como las alteraciones anatómicas, los desórdenes fisiológicos y las desviaciones biológicas dentro del conjunto de un concierto neurometabólico. Sin embargo aquí también nos encontramos con una importante objeción, esta vez mejor fundamentada y que no apela al sentido común. Se trata de la viabilidad de una teoría cuántica de la consciencia (Quantum consciousness theory) propugnada por el físico y matemático Roger Penrose de la Universidad de Oxford. Penrose rescata argumentos de la filosofía, las matemáticas, la física, la biología y la psicología para entender la dinámica de la consciencia en los términos de la física extendida: además de la relatividad, la mecánica cuántica. Por ejemplo, se sabe que en la retina humana hay células con sensibilidad hasta para un solo fotón; entonces, así como la retina forma parte del sistema nervioso, se infiere que en éste hay ciertos tipos de sensibilidad a otras partículas subatómicas que estarían regidas por los principios de la física cuántica. La dualidad onda/partícula en mecánica cuántica es el concepto de que no hay distinción entre ondas y partículas; las partículas pueden a veces comportarse como ondas y las ondas como partículas. El principio de incertidumbre de Heisenberg estipula que nunca puede estarse seguro acerca de la posición y la velocidad de una partícula en el espacio subatómico; cuanto con más exactitud se conozca una de ellas, con menos exactitud puede conocerse la otra. Para la teoría cuántica es imposible definir ambas, la posición y el momento de una partícula al mismo tiempo. Tan pronto se establecen los parámetros de movimiento de un cuerpo, su posición es incierta y puede sólo ser descrita matemáticamente como una onda u órbita de probabilidad. Un punto de vista cuántico de la consciencia reconoce que en su raíz, nuestra consciencia se comporta como el flujo incuantifícable del mundo subatómico. El cerebro puede así ser visto como un sutil dispositivo que amplifica los eventos cuánticos.

El postulado de que la mecánica cuántica y la consciencia humana están ligadas está basado en el principio de que el acto de ponderación, que implica a un observador consciente, tiene un efecto sobre los eventos cuánticos; un observador no puede 
divorciar su consciencia de los eventos observados. Penrose en conjunción con Stuart Hameroff de la Universidad de Arizona, propone que la conexión de los estados cuánticos con los de la física clásica ocurre dentro de ciertas proteínas llamadas microtúbulos, que son estructuras largas y huecas que forjan caminos para el transporte de vesículas, organelos y otros elementos de la arquitectura citológica. Estos microtúbulos cerebrales estarían dispuestos para desempeñar la transformación física ("switch"), produciendo «ocasiones de experiencia» que, con el fluir del tiempo, animan la corriente del pensamiento consciente (se ha calculado que el número de interconexiones existentes en el cerebro humano excede al número de átomos existentes en todo el universo; en este sentido el microcosmos parece corresponder al macrocosmos). Como quiera que la colocación física de una idea o de un pensamiento puede ser soportada sólo por un lapso corto de tiempo, la cuota cuántica debe ser reintegrada,y el punto de nuestra consciencia es forzado a dar un «salto» hacia otro estado cuántico, pero en otra región del cerebro. Así no hay un «libre albedrío» determinado por leyes físicas computables y nuestros pensamientos son constantemente interferidos por emociones, percepciones, recuerdos, imágenes fantásticas, etc. El «salto cuántico» no es determinista e introduce un elemento completamente aleatorio en la evolución temporal de la mente consciente, inmersa en el cauce de las asociaciones pautadas según patrones de acción previos. Dichos circuitos de probabilidad indeterminada funcionan más allá de la actividad biofísica mensurable por la consciencia.

Añadiremos, en lo que a la psicosis respecta, cierta información reciente proporcionada por científicos ingleses, que reporta la presencia disminuida de la expresión de una proteína asociada a los microtúbulos (microtubule-associated protein $M A P$ ) en el hipocampo (sistema límbico) en pacientes esquizofrénicos. Se sugiere que los cambios de esta proteína asociada a los microtúbulos en la esquizofrenia son mucho más complejos de lo que antes se presumía.

Considerando que este dato supondría una menor actividad cuántica en el cerebro de estos pacientes, aventuramos la conjetura de que, quizás, la psicosis se contacta de un modo más cercano a «las cosas»-significados- de la materia en la «realidad objetiva»; aquellas que corresponden al dominio de la física clásica. En todo caso, aunque no podamos formular por el momento ninguna definición conclusiva, ni mucho menos, en lo tocante a la etiología general de las psícosis, tenemos en cuenta que la presencia e importancia de: la subjetividad ha cobrado una fuerza inusitada en la ciencia contemporánea, insospechada hasta hace muy pocos años. Hipótesis: los procesos imponderables e indeterminables cuánticos vendrían a ser la cualidad distintiva de lo psíquico o mental, diferenciados del resto del organismo vivo y del mundo material regido por la física clásica determinista. Se instala en el discurso científico un antiguo criterio filosófico que situaba al sujeto y a lo subjetivo en un plano de primer orden. 


\section{ALGUNAS SUGERENCIAS PARA LA INVESTIGACIÓN}

Del contenido de la información recién presentada se desprenden algunas consideraciones que pueden orientar la investigación científica a múltiples niveles desde diversas áreas del conocimiento:

1. A través de las nuevos instrumentos en imagenología cerebral computarizada (PET, SPECT y otros más especializados en seguro advenimiento) podrán estudiarse experimentalmente a los neonatos pertenecientes a poblaciones de riesgo genétíco, y determinar correlaciones o analogías en los patrones fisiopatológicos de la dopamina y de otras sustancias que podrían estar involucradas en lo que M. Klein denominó "posición esquizoparanoide" en lo referente al tipo de ansiedad persecutoria eminentemente psicótica experienciada durante los primeros dos meses de vida. Investigaciones experimentales permitirían comprobar o rebatir un aspecto de la validez de esta teoría.

2. Analizar vínculos más específicos entre las alteraciones en el ventrículo, en el sistema límbico y en la corteza prefronatal y temporal izquierda, y de otras estructuras cerebrales, con la presentación de la enfermedad. Estudios epidemiológicos comparativos o correlacionales permitirían identificar grupos de riesgo a desarrollar psicosis y posibilitarían la verificación de tales malformaciones anatómicas como propiamente patognomónicas de la esquizotrenia.

3. La terapia genética es un procedimiento novedoso para el tratamiento de enfermedades con base genética, y consiste en introducir un nuevo ADN al cromosoma para reemplazar genes defectuosos y realizar su trabajo. Este tratamiento especializado demanda mucha precaución en cuanto a las variaciones irreversibles que pudiera inferir al genoma, y aquí se tocan consideraciones éticas. Cabría investigarse las posibilidades de este tratamiento para las psicosis donde, sabemos, están implicados genes en varios cromosomas. Si este tipo de información estuviera disponible por ciertas autoridades, ¿se afectarían de alguna manera los derechos de las personas de quienes se supiera tienen genes detectuosos para estas enfermedades'! ¿ Tendríamos el "derecho" de exigir en nuestros hijos determinados rasgos físicos o intelectuales por afectaciones del genoma? Estas inquietudes forman parte de la discusión ética.

4. Desde que se reconoce una disminución de la MAP asociada a los microtúbulos en el sistema límbico de pacientes esquizofrénicos, el consiguiente decrecimiento de la actividad cuántica en esos cerebros sería materia de especulación científica para la biofísica a la luz de las modernas aportaciones de S. Hameroffy R. Penrose en lo concerniente a la teoría cuántica de la consciencia. 
5. El lenguaje virtual interactivo engendrado en las redes del ciberespacio del mundo globalizado presenta un campo extraordinariamente fértil para la labor exploradora de psicoanalistas, así como de lingüistas y filólogos en indagar sobre los fenómenos de código observados en pacientes esquizofrénicos conectados a la internet. El ámbito de un lenguaje artificial restricto y de dominancia universal posibilita su manipulación controlada y análisis, y un examen bastante más minucioso que el que depararía un idioma formal o una terminología técnica.

6. La medida en que mejor se conozca el origen general de las enfermedades mentales, buscando su elucidación integral y las relaciones de causa-efecto en su presentación, dará la pauta de los modelos de tratamiento más eficaces y además redundará en el diseño de ofertas viables y óptimas de prevención.

7. Opino que el peor de los lastres que vive enquistado en el corazón axiológico de la psicología y del psicoanálisis. actualmente y en nuestro medio, es la persistencia encubierta de las creencias dualistas del psique/soma o alma/cuerpo. Considero que los psicoanalistas no necesitan recurrir a argumentos humanitaristas, espiritualistas o providenciales para defenderse de su temor al avance vertiginoso de la ciencia en lo que compete al área de la salud mental. No son aquellos argumentos solventes. Tampoco los psicólogos necesitan arrogarse cientificismo en desmedro del psicoanálisis, pues la psicología no es científica, y lo más parecido a ciencia dentro de la psicología no toma en cuenta las causas sino sólo los efectos de la enfermedad mental, obteniendo así siempre sólo resultados superficiales. Quizás de allí provenga el recelo perenne y la inseguridad de los psicólogos de atender cuadros clínicos más o menos graves como las psicosis. Del lado de la medicina, los tratamientos unilateralmente farmacológicos han demostrado ser una práctica nociva, o, por lo menos nada provechosa para la recuperación de pacientes psicóticos. Esta actitud refleja en el mejor de los casos una visión reduccionista de la etiología de los padecimientos mentales. Mientras no se combatan y eliminen todas estas prácticas perniciosas, la clínica seguramente no remontará mucho más allá de los manicomios. 


\section{BIBLIOGRAFÍA}

\section{AMERICAN PSYCHIATRIC ASSOCIATION}

"Manual diagnóstico y estadístico de los trastornos mentales DSM-1V"

Talleres Gráficos Dúplex. Barcelona, 1995.

2. CARLSON Neil «Fundamentos de fisiología psicológica»

Prentice Hall Hispanoamericana S.A. México, 1996.

3. COTTER D., KERWIN R., DOSHI B., MARTINCS., EVERALLIP

"Alterations in hippocampal nonphosphorylated MAP2 protein expression in schizophrenia" Institute of Psychiatry. London, 1997.

4. DE LA FUENTE Ramón, ALVAREZ Francisco «Biología de la mente» Fondo de Cultura Económica. México, 1998.

5. FREUD Sigmund «Obras completas» Biblioteca Nueva. Madrid, 1973.

6. GUYTON Arthur «Anatomía y fisiología del sistema nervioso, neurociencia básica» Ed. Médica Panámericana. Buenos Aires, 1989.

7. HAMEROFF Stuart, PENROSE Roger "Journal of consciousness studies: Conscious events as orchestrated spacetime selections" University of Arizona / University of Oxford, 1996.

8. KLEIN Melanie "Contribuciones al psicoanálisis" Paidós. Buenos Aires, 1964.

9. LACAN Jacques «Escritos» Siglo XXI.

México, 1980.

10. LACAN Jacques «El seminario III, las psicosis» Paidós. Buenos Aires, 1997.

11. NATIONAL GEOGRAPH1C October 1999 "Secrets of the gene" National Geographic Society. Washington DC, 1999.

12. SAUSSURE Ferdinand de "Curso de lingüística general" Alianza Ed. Madrid, 1987.

13. SEGAL Hanna «Introducción a la obra de Melanie Klein»Paidós. Buenos Aires, 1972. 